\title{
Biological and Chemical Studies of Essential Oil from Vitex negundo of Nepalese Origin
}

\author{
Ishwor Pathak ${ }^{1 *}$, Muna Niraula ${ }^{2}$ and Prakash Thapa ${ }^{2}$ \\ ${ }^{1}$ Department of Chemistry, Amrit Campus, Tribhuvan University, Kathmandu, Nepal \\ ${ }^{2}$ Central Department of Chemistry, Tribhuvan University, Kirtipur, Kathmandu, Nepal \\ Email: pathakishwor14@gmail.com
}

\begin{abstract}
In this study, essential oil from air dried leaves, flowers and fruits of the Vitex negundo was extracted by hydro distillation using Clevenger apparatus and chemical compositions of the essential oil was analyzed by performing GC analysis which revealed the presence of 31 compounds, most of them were monoterpenes, sesquiterpenes, monoterpene alcohols, sesquiterpene alcohols, diterpenes, cyclic and bicyclic alcohols. Some compounds were naphthalene, pyradizine and pyrazole derivatives also. The major constituents present in the oil sample was 2-methylene-4,8,8-trimethyl-4-vinylBicyclo[5.2.0]nonane (26.83\%). Biological activity of the essential oil was tested by performing brine shrimp bioassay. The oil tested was found to be cytotoxic against brine shrimps as shown by its $L C_{50}$ value of 51.52 much below the accepted maximum potential value of 1000.
\end{abstract}

Keywords: Vitex negundo, essential oil, GC analysis, Brine shrimp bioassay

\section{Introduction}

A natural product is a chemical compound or substance produced by living organisms found in nature that usually has a pharmacological or biological activity and can be used in pharmaceutical drug discovery and drug design ${ }^{1}$. Sources of natural product are plants, animals and microorganisms, which can be terrestrial or marine. Some examples of natural products are steroids, terpenoids, flavonoids, alkaloids, quinones, polyphenols etc. ${ }^{1}$.

Herbal medicine is the oldest form of healthcare to mankind and it will be not an exaggeration to say that use of herbal healthcare is probably as ancient as mankind ${ }^{2}$. With change in time and development of science and technology, the traditional medicine has become the precursor for today's modern medicine and finally the boon to human ${ }^{3}$. Despite of tremendous progress in human medicines, infectious diseases caused by bacteria, fungi, viruses and parasites are still a major threat to public health. The increasing failure of chemotherapeutics and antibiotic resistance exhibited by pathogenic microbial infectious agents has led to the screening of several medicinal plants for their potential biological activity ${ }^{4}$. Therefore, natural product chemistry has become an important site to explore the biological and pharmaceutically active components from plants ${ }^{5}$.

\footnotetext{
* Corresponding author
} 
In Nepal, there are thousands of medicinally important plants among which 1,100 species are very important in terms of biological activity ${ }^{6}$. The present study is focused on biological and chemical studies of the essential oil from Vitex negundo plant of Nepalese origin. An essential oil is natural oil typically obtained from distillation and having the characteristic odour of the plant or other sources from which it is extracted. They are natural aromatic compounds found in seeds, bark, root, flowers and other parts of the plant $^{7}$. They consist of a complex mixture of mono- and sesquiterpenes, phenyl propanoids and oxygenated compounds ${ }^{8}$.

Vitex negundo Linn. (Verbenaceae) is commonly known as Simali (Nepali), Nirgundi (Hindi) and five leaved chaste tree (English) ${ }^{9}$. It is found in moist area throughout Nepal up to an altitude of 1500 meter. It also grows widely in other Indian subcontinents, central Asia, Europe, northern America and eastern Africa. It is an aromatic large shrub or small slender tree of about 2 to 3 meter in height and commonly bears tri- or penta-foliate leaves on quadrangular branches, which gives rise to bluish-purple colored flowers. The fruit is succulent, black and rounded when ripe having about $4 \mathrm{~mm}$ in diameter ${ }^{9,10}$.

Vitex negundo (Linn.) is one of the common plants used in traditional medicine and reported to have variety of pharmacological activities. Although, all parts of $V$. negundo are used as medicine in the indigenous system of medicine, the leaves are the most potent for medicinal use ${ }^{8}$. The decoction of leaves is used for treatment of inflammation, eye disease, toothache, leucoderma, enlargement of spleen, ulcers, cancers, catarrhal fever, rheumatoid arthritis, gonorrhea, sinuses, scrofulous sores, bronchitis and as tonics, antimicrobial, antibacterial, antipyretic, analgesic, insecticidal, anti-oxidant, growth inhibition and morphogenetic agents ${ }^{11}$. The root is considered as tonic, febrifuge and expectorant, arthritis, dyspepsia, colic, rheumatism, leprosy, dysentery, urinary disorders, wounds, ulcers, malarial fever and skin diseases. The root is also an antidote to snake venom. Flowers are used in diarrhea, cholera, fever, hemorrhages, hepatopathy and cardiac disorders. The essential oils and extracts produced by the plant's secondary metabolites is responsible for these various pharmacological activities ${ }^{12}$.

\section{Experimental Methods}

\section{Collection of plant materials}

The fresh leaves, flowers and fruits of Vitex negundo were collected in October 2017 from Dhading district of Nepal. The taxonomic identification of plant was confirmed at Department of Botany, Amrit Campus, Lainchour, Kathmandu. The collected fresh plant materials were washed with tap water to remove the contaminants like dust, soil, insect's larvae or insects too and other unwanted attached particles on the plant.

\section{Extraction of essential oils}

The essential oil from the leaves, flowers and fruits of Vitex negundo was extracted by hydro distillation using closed type Clevenger apparatus for extraction of oils lighter than water. 100 grams of fresh leaves, flowers and fruits of $V$. negundo were cut into small pieces and kept into hard glass round flask along with some distilled water. The content of the flask was heated to boiling. Heating was continued for 6 hours and allowed to stand for some time and the stopper of the Clevenger apparatus was opened. The water was drawn out slowly until the surface of the oil layer corresponded to the preparation line and allowed to stand for some time. The surface of the layer was lowered to zero line and the volume 


\section{J. Nepal Chem. Soc., Vol. 39, 2018}

of the oil was measured at the same condition. The process was repeated several times and percentage yield of essential oil was calculated. Finally, the oil was collected in a glass vial over dry $\mathrm{Na}_{2} \mathrm{SO}_{4}$ and stored in a sealed glass bottle in a refrigerator until further experiment was performed.

\section{GC Analysis}

$\mathrm{GC}$ analysis of the essential oil was carried out on a gas chromatography mass spectrometer and the volatile oil components were identified by comparing their retention indices of GC chromatogram with those of literature and authentic standards available in the laboratory. GC analysis was performed under the following conditions: injection volume $1 \mu \mathrm{L}$ with split ratio 1:90; Helium as a carrier gas, temperature maintained at $40{ }^{\circ} \mathrm{C}$; electron impact mode of ionization with ionization energy $70 \mathrm{eV}$ and ion source temperature $170^{\circ} \mathrm{C}$.

\section{Biological Screening}

Biological screening involves the study of effect of the essential oil at arbitrarily fixed dose levels in a species of organism and prediction of its effect over the entire dosage range. It helps to confirm the biological activity of medicinal plant. In order to test the biological activity of the essential oil, brine shrimp bioassay has been carried out by following standard protocol ${ }^{13}$.

\section{Brine Shrimp Bioassay}

Brine shrimp bioassay process involves introducing the newly hatched brine shrimp naupalii to the crude plant extracts/ fractions. The method determines the $\mathrm{LC}_{50}$ values (Lethal concentration for $50 \%$ mortality) for the crude extracts. Compound of $\mathrm{LC}_{50}$ values less than $1000 \mathrm{ppm}$ are considered as potentially pharmacologically active ${ }^{13}$.

In order to hatch the shrimps, about $50 \mathrm{mg}$ of brine-shrimp eggs were sprinkled on the beaker filled with artificial sea water and illuminated with table lamp ( 60 watt) for 48 hours by adjusting temperature at $30^{\circ} \mathrm{C} .20 \mathrm{mg}$ of the sample essential oil was dissolved in $2 \mathrm{~mL}$ acetone. The solution thus prepared was used as stock solution. The test was conducted in test tubes and sterilized sea water (final volume $10 \mathrm{~mL}$ ). From each stock solution, $500 \mu \mathrm{L}$ (eqv. $1000 \mathrm{ppm}$ ), $50 \mu \mathrm{L}$ (eqv. 100 ppm), $5 \mu \mathrm{L}$ (eqv. $10 \mathrm{ppm}$ ) were transferred to total nine test tubes, three tubes for each doses level. Then, the solvent was evaporated by standing overnight. After complete evaporation of solvent, ten matured shrimps in $5 \mathrm{~mL}$ artificial sea water were transferred to all test tubes containing samples. Similarly, three controlled vials were taken and ten matured nauplii were introduced in each vial. After 24 hours of illumination under a table lamp (60 Watt), the numbers of survivor were counted with the help of disposable pipettes. $\mathrm{The}^{\mathrm{LC}} \mathrm{C}_{50}$ value was determined using probit regression.

\section{Results and Discussion}

The percentage yield of the essential oil from leaves, fruits and flowers of $V$. negundo was found to be $0.2 \%(\mathrm{v} / \mathrm{w})$ on a fresh weight basis and the collected oil was found to have following organoleptic properties. 
Table 1. Organoleptic properties of essential oil from Vitex negundo

\begin{tabular}{|c|l|l|l|}
\hline Plant & \multicolumn{1}{|c|}{ Appearance } & \multicolumn{1}{c|}{ Color } & Aroma \\
\hline Vitex negundo & $\begin{array}{l}\text { Slightly viscous and } \\
\text { non-sticky }\end{array}$ & Pale yellow & $\begin{array}{l}\text { Pleasant, strongly } \\
\text { fragrant }\end{array}$ \\
\hline
\end{tabular}

The GC analysis of the essential oil of leaves, flowers and fruits of Vitex negundo revealed the presence of 31 compounds. Among the identified compounds, 8 were monoterpenes, 2 were momoterpene alcohols, 5 were sesquiterpenes, 2 were sesquiterpene alcohols, 2 were bicyclic sesquiterpenes, 1 was bicyclic diterpene alcohol and the remaining compounds include 3 naphthalene derivatives, 2 pyradizine derivatives, 2 pyrazol derivatives and some cyclic and bicyclic alcohols. Constituents of essential oil of Vitex negundo are tabulated below.

Table 2. Chemical constituents of essential oil from Vitex negundo

\begin{tabular}{|c|c|c|c|}
\hline S.N. & Name of compound & $\begin{array}{l}\text { Retention } \\
\text { Time }\left(\mathbf{R}_{\mathrm{t}}\right)\end{array}$ & Area \% \\
\hline 1. & $\alpha$-Pinene & 11.723 & 10.73 \\
\hline 2. & Sabinene & 13.562 & 4.29 \\
\hline 3. & $\beta$-Pinene & 13.701 & 0.64 \\
\hline 4. & Myrcene & 14.400 & 1.67 \\
\hline 5. & $\alpha$-Phellandrene & 15.012 & 1.48 \\
\hline 6. & Para-Cymene & 15.997 & 1.08 \\
\hline 7. & $\beta$-Phellandrene & 16.211 & 11.35 \\
\hline 8. & $\gamma$-Terpinene & 17.681 & 0.47 \\
\hline 9. & 3,7-dimethyl-1,6-Octadien-3-ol & 19.692 & 0.31 \\
\hline 10. & Terpinen-4-ol & 23.463 & 0.58 \\
\hline 11. & 2-methylene-4,8,8-trimethyl-4-vinyl-Bicyclo[5.2.0]nonane & 34.487 & 26.83 \\
\hline 12. & $\beta$-E-Farnesene & 35.871 & 14.00 \\
\hline 13. & $\alpha$-Curcumene & 36.990 & 0.34 \\
\hline 14. & Selina-4,11-diene & 37.110 & 0.32 \\
\hline 15. & $\gamma$-Muurolene & 37.505 & 0.69 \\
\hline 16. & $\alpha$-Elemol & 39.700 & 0.32 \\
\hline 17. & Diethyl-4,4-azoxydibenzoate & 39.922 & 0.32 \\
\hline 18. & Caryophyllene oxide & 41.112 & 1.59 \\
\hline
\end{tabular}


J. Nepal Chem. Soc., Vol. 39, 2018

\begin{tabular}{|c|c|c|c|}
\hline 19. & Hinesol & 43.770 & 0.31 \\
\hline 20. & $\begin{array}{l}\text { 1-[3-(2,6,6-Trimethyl-cyclohex-2-enyl)-4,5-dihydro-3[1- } \\
\text { pyrazol-4-yl]-ethanone }\end{array}$ & 51.140 & 8.48 \\
\hline 21. & $\begin{array}{l}\text { 6-Isopropenyl-4,8a-dimethyl-1,2,3,5,6,7,8,8a- } \\
\text { octahydronapthalene-2,3-diol }\end{array}$ & 51.790 & 3.22 \\
\hline 22. & $\begin{array}{l}\text { Decahydro-1,1,4a-trimethyl-6-methylene-5-(3-methyl-2,4- } \\
\text { pentadienyl Napthalene }\end{array}$ & 52.213 & 3.17 \\
\hline 23. & 1-(4-fluorophenyl)-4-pentyl-Cyclohexanol & 53.280 & 0.50 \\
\hline 24. & $\begin{array}{l}\text { 1-[3-(2,6,6-Trimethyl-cyclohex-2-enyl)-4,5-dihydro-3[1- } \\
\text { pyrazol-4-yl]-ethanonone }\end{array}$ & 53.934 & 1.54 \\
\hline 25. & $\begin{array}{l}\text { [6,8,9-trimethyl-4-(2-furyl)-3-oxabicyclo[3.3.1]non-6-en-1- } \\
\text { yl]-Methanol }\end{array}$ & 54.056 & 1.82 \\
\hline 26. & $\begin{array}{l}\text { 1,4,4a,5,6,9,10,10a-octahydro-11,11-dimethyl-1,4- } \\
\text { Methanocycloocta[d]pydidazine }\end{array}$ & 54.356 & 0.66 \\
\hline 27. & $\begin{array}{l}\text { 1-[3-(2,6,6-Trimethyl-cyclohex-2-enyl)-4,5-dihydro-3H- } \\
\text { pyrazol-4-yl]-ethanone }\end{array}$ & 55.204 & 0.95 \\
\hline 28. & $\begin{array}{l}\alpha \text {-ethenyldecahydro- } \alpha-5,5,8 \text { a-tetramethyl-2-met-1- } \\
\text { Napthalenepropanol }\end{array}$ & 55.428 & 0.32 \\
\hline 29. & $\begin{array}{l}\text { 1,4,4a,5,6,9,10,10a-octahydro-11,11-dimethyl-1,4- } \\
\text { methanocycloocta[d]pyridazine }\end{array}$ & 56.048 & 0.97 \\
\hline 30. & Manool & 57.792 & 0.37 \\
\hline 31. & $\begin{array}{l}\text { 14,15-didehydro- } 1,4,5,8,9,10,11,12,13,16,17,18,19,20- \\
\text { cyclodecacyclotetradecene }\end{array}$ & 58.250 & 0.72 \\
\hline
\end{tabular}

Investigation of essential oil of Vitex negundo reported 2-methylene-4,8,8-trimethyl-4-vinylBicyclo[5.2.0]nonane as a predominant constituent (26.83\%). Similarly, $\beta$-E-Farnesene (14.00\%), $\alpha$ Pinene (10.73\%), $\beta$-Phellandrene (11.35\%), 1-[3-(2,6,6-Trimethyl-cyclohex-2-enyl)-4,5-dihydro-3[1pyrazol-4-yl]-ethanone (8.48\%), Sabinene (4.29\%), 6-Isopropenyl-4,8a-dimethyl-1,2,3,5,6,7,8,8aoctahydronapthalene-2,3-diol (3.22\%) and Decahydro-1,1,4a-trimethyl-6-methylene-5-(3-methyl-2,4pentadienyl Napthalene (3.17\%) were also reported in considerable amount in GC analysis of the oil.

Extensive literature survey revealed that most of the compounds found in the oil has been reported in different articles that has been already published ${ }^{10,11,15,16}$. However, the most predominant compound 2methylene-4,8,8-trimethyl-4-vinyl-Bicyclo[5.2.0]nonane has not been reported anywhere in the volatile oil from $V$. negundo till date. Tan et al ${ }^{14}$ reported that this compound exhibit anti-inflammatory and antibacterial activities ${ }^{14,17}$. 


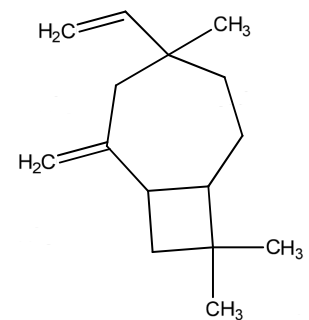

Fig 1. 2-methylene-4,8,8-trimethyl-4-vinyl-Bicyclo[5.2.0]nonane

In this study, $\mathrm{LC}_{50}$ values $(\mu \mathrm{g} / \mathrm{mL})$ for the oil from Vitex negundo was evaluated. $\mathrm{LC}_{50}$ value is the lethal concentration dose required to kill $50 \%$ of the shrimps. Values less than $1000 \mu \mathrm{g} / \mathrm{mL}$ are supposed to be pharmacologically active.

The essential oil from Vitex negundo was found to be cytotoxic against brine shrimps as shown by its $\mathrm{LC}_{50}$ value of 51.52 much below the accepted maximum potential value of 1000 .

\section{Conclusions}

Leaves, fruits and flowers of Vitex negundo from Dhading district of Nepal was collected and essential oils from the collected plant materials has been isolated. Biological and chemical studies on the isolated essential oil have been successfully carried out. Based on the results of the study, the essential oil was found to be highly toxic against brine shrimp nauplii having $\mathrm{LC}_{50}$ value 51.52. GC analysis result showed that the compound 2-methylene-4,8,8-trimethyl-4-vinyl-Bicyclo[5.2.0]nonane was found to be the predominant bicyclo compound $(26.83 \%)$ in the oil along with $\beta$-E-Farnesene $(14.00 \%), \alpha$-Pinene (10.73\%), $\beta$-Phellandrene (11.35\%) and 1-[3-(2,6,6-Trimethyl-cyclohex-2-enyl)-4,5-dihydro-3[1-pyrazol4 -yl]-ethanone $(8.48 \%)$ as other major compounds. Since, the essential oil is cytotoxic and the major bicyclo compound shows anti-inflammatory and antibacterial activities ${ }^{14}$, this plant can be exploit as plant based drugs.

\section{Acknowledgements}

One of the author would like to thank Institute of Science and Technology, Office of the Dean, Trihuvan University, Kirtipur, Nepal for financial support to carry out this research. Authors are also thankful to Head of Chemistry Department, Amrit Campus, for providing laboratory facility, Department of Plant Resources, for providing technical support to perform GC analysis of essential oil.

\section{References}

1. N.P. Manandhar, Plants and people of Nepal, Timber press, Portland, USA, 2002, .pp 599.

2. R.T. Vishal, Nat. Prod. Rad., 2005, 4, 162-165.

3. P.C. Trivedi, Agrobiosis., 2006, 3, 1-25.

4. S.D. Sarker, Z. Lalif, and A. I. Gray, Natural Products Isolation, Second edition, Humana Press Inc., 2005, p89-122.

5. H. Yuan, Q. Ma, L. Ye, and G. Piao, Molecules., 2016, 21, 559-565. 


\section{J. Nepal Chem. Soc., Vol. 39, 2018}

6. S. Brindha, T. Thamaraiselvi, B. Annadurai and S.K. Gangwar, Int. J. of Adv. Bio. Res., 2012, 2(2), 298-302.

7. P. Seenivasan, J. Manikkam, and Savarimuthu, J. of Int. Soc. for Comp. Med. Res., 2006, 6, 3639.

8. S. Rana and K.K. Rana, Scientific Research, 2014, 1, 1-13.

9. A.S. Vishwanathan and R. Basavaraju, EJBS, 2010, 3, 30-42.

10. A.K. Meena, U.S. Niranjan, M.M. Rao, M.M. Padhi and R. Babu, Asian J. of Trad. Med., 2011, 6, 54-60.

11. L.N. Gautam, S.L. Shrestha, P. Wagle and B.M. Tamrakar, Scientific world, 2008, 6, 27-32.

12. V. Singh, R. Dayal and J.P. Bartley, Organic Letters, 1999, 65, 580-582.

13. Q.S. Sarah, F. Chowdhury and M. Mishuddin, Bang. J. of Pharm., 2017, 12, 186-189.

14. W.N. Tan, K.C. Wong, M. Khairuddean, I.M. Elden, Z. Asmawi, and B. Sulaiman, Flav. and Frag. J., 2012, 10, 134-137.

15. P. Singh, G. Mishra, K.K. Jha, V.K. Garg and R.L. Khosa, Int. J. of Chem. Tech. Res., 2010, 2, 1686-1690.

16. G.R. Mallavarapu, S. Ramesh, P.N. Kaul, A.K. Bhattacharya and B. R. Rejeswara, Letters, 1994, 60, 582-585.

17. R.S. Farg, F.M. Hewadi and G.S. Elbaroty, J. of Food Prot., 1987, 52(9), 665-667. 